\title{
Classifying Hybrids of Energy Cane for Production of Bioethanol and Cogeneration of Biomass-Based Electricity by Principal Component Analysis-Linked Fuzzy C-Means Clustering Algorithm
}

\author{
B. R. A. Moreira ${ }^{1}$, R. S. Viana ${ }^{2}$, L. A. M. Lisboa ${ }^{2}$, P. R. M. Lopes ${ }^{2}$, P. A. M. Figueiredo ${ }^{2}$, S. B. Ramos ${ }^{2}$, \\ C. S. B. Bonini ${ }^{2}$, V. D. R. Trindade ${ }^{1}$, M. G. O. Andrade ${ }^{1} \&$ A. May ${ }^{3}$ \\ ${ }^{1}$ Faculty of Engineering of Ilha Solteira, São Paulo State University, São Paulo, Brazil \\ ${ }^{2}$ College of Agricultural and Technological Sciences, São Paulo State University, São Paulo, Brazil \\ ${ }^{3}$ Embrapa Environment, Brazilian Agricultural Research Corporation, São Paulo, Brazil \\ Correspondence: Ronaldo S. Viana, College of Agricultural and Technological Sciences, São Paulo State \\ University, São Paulo, Brazil. Tel: 55-183-821-7476. E-mail: ronaldo.viana@unesp.com
}

Received: May 3, $2019 \quad$ Accepted: June 29, $2019 \quad$ Online Published: August 31, 2019

doi:10.5539/jas.v11n14p246 URL: https://doi.org/10.5539/jas.v11n14p246

\begin{abstract}
The biggest challenge facing in sugar-energy plants is to move towards the biorefinery concept, without threatening the environment and health. Energy cane is the state-of-the-art of smart energy crops to provide suitable whole-raw material to produce upgraded biofuels, dehydrated alcohol for transportation, refined sugar, yeast-fermented alcoholic beverages, soft drinks, silage and high-quality fodder, as well as to cogenerate heat and bioelectricity from burnt lignocellulose. We, accordingly, present fuzzy c-means (FCM) clustering algorithm interconnected with principal component analysis (PCA) as powerful exploratory data analysis tool to wisely classify hybrids of energy cane for production of first-generation ethanol and cogeneration of heat and bioelectricity. From the orthogonally-rotated factorial map, fuzzy cluster I aggregated the hybrids VX12-0277, VX12-1191, VX12-1356 and VX12-1658 composed of higher contents of soluble solids and sucrose, and larger productive yields of fermentable sugars. These parameters correlated with the X-axis component referring to technological quality of cane juice. Fuzzy cluster III aggregated the hybrids VX12-0180 and VX12-1022 consisted of higher fiber content. This parameter correlated with the Y-axis component referring to physicochemical quality of lignocellulose. From the PCA-FCM methodology, the conclusion is, therefore, hybrids from fuzzy cluster I prove to be type I energy cane (higher sucrose to fiber ratio) and could serve as energy supply pathways to produce bioethanol, while the hybrids from fuzzy cluster III are type II energy cane (lower sucrose to fiber ratio), denoting potential as higher fiber yield biomass sources to feed cogeneration of heat and bioelectricity in high temperature and pressure furnace-boiler system.
\end{abstract}

Keywords: alternative clean energy sources, exploratory data analysis, FCM algorithm, fiber-rich biomass, PCA

\section{Introduction}

Brazil ranking first in the sugarcane production worldwide, followed by India, and the People's Republic of China. In this continental-scale tropical country, sugarcane fields extend for roughly 10 million hectares as recorded from Major Crops Bulletin issued regularly by Ministry of Agriculture, Livestock and Supply (MAPA). The state of São Paulo is the main sugarcane growing area, holding over fifty-percent of domestic production of bioethanol from cane juice. However, as new crop lands emerge due to industrial decentralization, sugarcane mill plants, biorefineries and distilleries extensively move from Southeast to Midwest and Northeast, where biotic and abiotic factors make sugar-energy sector planning difficult and expensive. Stress-tolerant genotypes are necessary to help sugarcane producers to mitigate external agents influencing productive yield and technological quality of sugar and biomass fields (Goldemberg et al., 2014; Defante et al., 2018).

Energy cane is the hybrid (Saccharum officinarum L. $\times$ S. robustum L. $\times$ S. spontaneum L.) from backcrossing between elite and wild species. Because of its improved morphophysiological traits such as larger canopy composing of large-size green leaves and deeper root system, energy-cane is higher efficient in $\mathrm{CO}_{2}$ fixation and mineral uptake from substantial soil depths, growing quicker than sugarcane crop in drylands. Apart from its characteristics of wider adaptability to harsh environments, larger commercial cycle and greater land-use, 
energy-cane has larger productivity of fiber-rich biomass. All these strengths contribute to energy cane to be one of the seemingly simplest and wisest renewable energy supply pathways to help sugar-energy plants to move towards the flexi-factory concept, without destroying the environment (Matsuoka et al., 2012; Koodaruth et al., 2014; Matsuoka et al., 2014).

Energy cane can be type I or type II. Type I is qualitatively and quantitatively closer to sugarcane crop, with a higher sucrose to fiber ratio and viability for production of biomass-to-solid, biomass-to-liquid and biomass-to-gaseous fuels, dehydrated alcohol for transportation, refined sugar, yeast-fermented alcoholic beverages, soft drinks, hydrolyzed silage and high-quality fodder. Type II has lower sucrose to fiber ratio, suitable low moisture lignocellulose to cogenerate heat and electricity in high temperature and pressure furnace-boiler system, as well as low-pressure steam for distillation of fuel and sugar cooking (Santchurn et al., 2012; Gouy et al., 2015; Ceccato-Antonini et al., 2017). Exploratory data analysis (EDA) tools such as principal component analysis and fuzzy c-means clustering algorithm could accurately classify genotypes of energy cane expected to supply sugar, ethanol and electricity markets into the next years.

Principal component analysis (PCA) is the oldest data analysis method used to reduce the dimensionality of larger data sets, while preserving as much variability as possible into orthogonally-rotated subsets or components without the presence of correlated variables. Fuzzy c-means (FCM) clustering algorithm is fuzzy logic-based unsupervised system for classification and recognition of patterns, well known for its simplicity and efficiency. However, it shows a trend to fall into local minima as weakness. Hybridization or optimization with other EDA approaches is necessary to apply successfully FCM, regardless scientific field (Nayak et al., 2015; Jolliffe \& Cadima, 2016). The scientific study by Gouy et al. (2015) on the effects of S. spontaneum L. introgression level on the sugarcane crop yield performance and its impact on the productivity in radiation and thermal conditions proved cluster analysis can robustly discriminate energy cane from sugarcane. The scientific study by Rao et al. (2016) on the mega-environments and two-tables methods for sugarcane yield studies described PCA algorithm is one of the most reliable EDA tools to generate insights from genotype-environment relationship and its impact on phenotype. Mansoori et al. (2016) reported FCM can classify powerfully genotypes developed in salinity and nutrient uptake environments.

We, accordingly, present FCM-PCA approach as powerful exploratory data analysis tool to accurately classify hybrids of energy cane for production of first-generation ethanol and cogeneration of heat and bioelectricity.

\section{Method}

\subsection{Location}

We performed the cultivation of hybrids of energy-cane in the experimental field at Caete sugarcane mill plant, located in the municipality of Paulicéia, state of São Paulo, Brazil, within 2015/16, 2016/17 and 2017/18 growing seasons. The soil of the area is eutrophic yellow-red Latosol, with sandy-loamy texture. According to Koppen-Geiger classification system, regional climate is Aw, with predominantly dry winters and rainy summers.

\subsection{Hybrids of Energy Cane}

The Brazilian biotechnological company Biovertis/Granbio kindly donated one-month-old seedlings of the hybrids VX12-0046, VX12-0180, VX12-0201, VX12-1022, VX12-1191, VX12-1356 and VX12-1658.

\subsection{Acclimation}

Acclimation facility consisted of an arch-type greenhouse, $6 \mathrm{~m}$ sides, constructed with a cover consisting of a one-layer transparent plastic film, with $50 \%$ light transmittance. Its interior contained polyethylene $20 \mathrm{~L}$ pots filled with sun-dried and sieved Latosol, then planted with $0.2 \mathrm{~m}$-height seedlings. Crop irrigation was three times a week for two months.

\subsection{Experimental Planning}

A randomized block design consisted of carrying out five $100 \mathrm{~m}$ length $\times 13.5 \mathrm{~m}$ width experimental plots served as replications for each hybrid.

\subsection{Soil Preparation and Crop Transplanting}

Soil preparation consisted of applying $2.0 \mathrm{tha}^{-1}$ dolomitic limestone and $0.6 \mathrm{t} \mathrm{ha}^{-1} \mathrm{NPK}$ fertilizer to respectively improve acidity and natural fertility. Two months from soil amendment, a sugarcane planter machine transplanted four-month-old seedlings into standardized plots composed of ten $100 \mathrm{~m}$-length planting furrows spaced at $1.5 \mathrm{~m}$ apart from each other. At the first and second ratoon seasons, fertilization management followed the technical recommendations of Raij et al. (1986). 


\subsection{Crop Harvesting and Assessment}

At the end of the second ratoon season, a sugarcane harvester machine harvested, $2.5 \mathrm{~m}$-height, three-year-old hybrids in the six central planting furrows of each plot. After removing leaves, a hydraulic press working at 25 MPa crushed $1.5 \mathrm{~m}$-length cane stalks, repeating three times. We collected and then assessed cane juice and lignocellulose samples for total soluble solids, sucrose, purity, reducing sugars, productive yield of fermentable sugars, fiber and productivity of dry biomass, as the methodologies detailed by Ahmed et al. (2010) and Viana et al. (2017).

\subsection{Data Analysis}

The descriptive analysis of crop performance consisted of calculating the measures of position and dispersion, mean, standard deviation and coefficient of variation. For the exploratory data analysis, the Pearson test assessed the strength of linear relationship between variables, with values ranging from 0 to 1 in absolute. Next the programing and running Bartlett's sphericity test and PCA algorithm in software R for statistical computing and graphics, the Kaiser-Meyer-Olkin (KMO) approach tested the number of principal components needed to reduce the dimensionality of the original data set, while preserving as much variability as possible into orthogonally-rotated subsets with significant eigenvalues. The Euclidian metric measured how similar or dissimilar were the hybrids of energy cane, classified through FCM clustering algorithm and then defuzzified as alternative clean energy sources for production of first-generation ethanol and/ or cogeneration of heat and bioelectricity (R Core Team, 2017).

\section{Results and Discussion}

\subsection{Principal Component of Technological Quality of Cane Juice and Physicochemical Quality of Lignocellulose}

From the orthogonally-rotated factorial map, two components with significant eigenvalues by KMO test at 0.95 confidence level jointly retained ninety-percent of variance within subset without correlated variables. Soluble solids, sucrose, purity, reducing sugars, moisture and productive yield of fermentable sugars correlated both positively and negatively with the horizonal component referred to technological quality of cane juice, while the fiber positively correlated with the vertical component referred to physicochemical quality of lignocellulose. Complementarily, productivity of dry biomass positively correlated with the Z-axis component. However, third component were insignificant to explain crop performance of hybrids of energy cane as proposed in Figure 1.

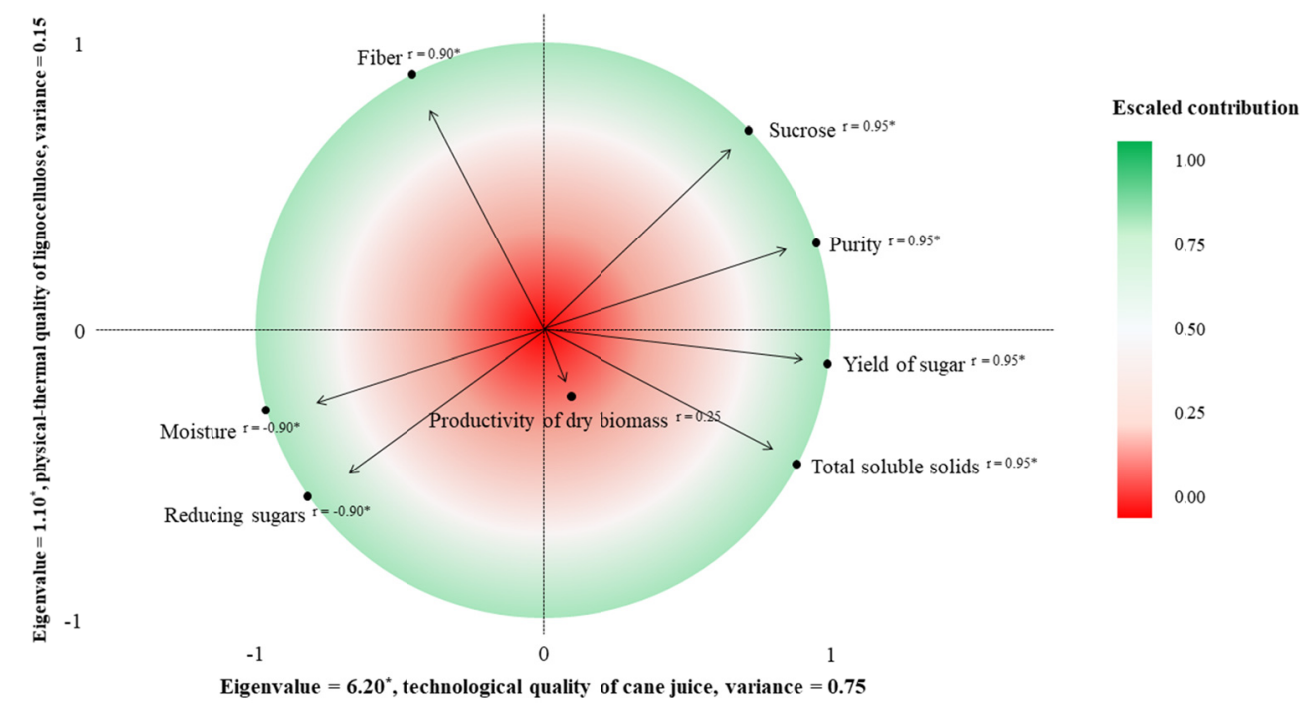

Figure 1. Orthogonally-rotated factorial map of parameters of technological quality of cane juice and physiochemical quality of lignocellulose of hybrids of energy-cane

Note. * Significant by Kaiser-Meyer-Olkin test at $\mathrm{P}<0.05$.

Total soluble solids, sucrose, purity, reducing sugars, moisture and productive yield of fermentable sugars equally contributed to technological quality of cane juice, while the fiber followed by moisture had the strongest standardized contribution to physicochemical quality of lignocellulose. If moisture was ambiguous, it was then one of the most relevant variables influencing both technological quality of cane juice and physicochemical 
quality. Other important discriminant was sucrose to fiber ratio, consistent with the study by Santchurn et al. (2012), who investigated multivariate data analysis techniques in the identification of high biomass yield crops.

PCA seemingly was simple but reliable to generate insights for the fuzzy logic-based classification of the hybrids of energy cane as renewable energy resources for production of first-generation ethanol and cogeneration of heat and electricity.

\subsection{Hybrids of Energy Cane for Production of Bioethanol and Cogeneration of Heat and Electricity}

PCA-FCM methodology proposed in Figure 2 defuzzified the hybrids of energy cane for the categories, first-generation ethanol, heat and bioelectricity, and unqualified, based on Euclidian distances between parameters of technological quality of cane juice and physicochemical quality of lignocelulose.

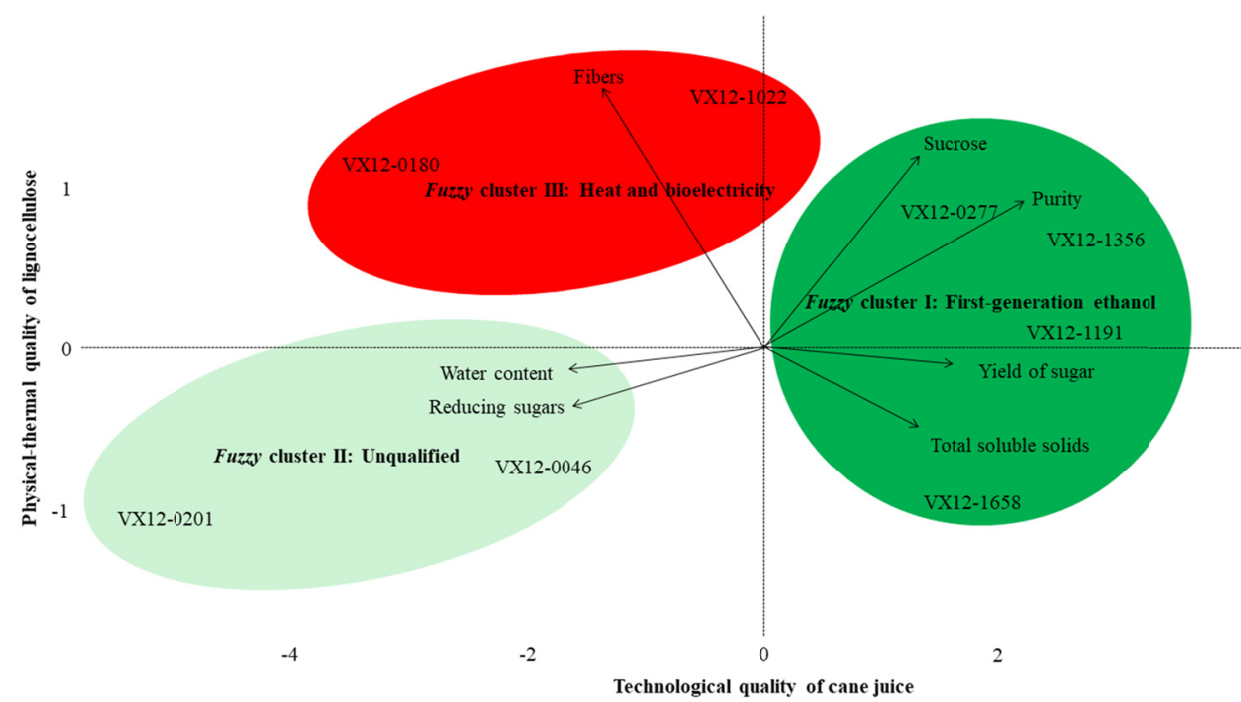

Figure 2. Biplot of hybrids of energy-cane classified through PCA-FCM methodology as renewable resources for production of first-generation ethanol and co-generation of heat and bioelectricity

Fuzzy cluster I aggregated the hybrids VX12-0277, VX12-1191, VX12-1356 and VX12-1658 composed of higher contents of soluble solids and sucrose, and larger productive yields of fermentable sugars. Higher purity stem-juice could guarantee yeasts performing well in the making first-generation ethanol. Fuzzy cluster II aggregated the hybrids VX12-0046 and VX12-0201 consisted of higher contents of water and reducing sugars. Higher moisture raw material could spend a larger part of thermal energy on water vaporization, instead of channeling it into only burning down lignocellulose, compromising cogeneration of heat, bioelectricity and low-pressure steam for distillation of fuel and sugar cooking. Also, chemical properties of water can convert sucrose into fructose and glucose by hydrolyzation. Larger availability of monosaccharides rather than sucrose could decline productive yield of refined sugar and bioethanol in sugar-energy plants (Bahadori et al., 2014). Thereby, hybrids of energy cane from fuzzy cluster II could not serve as feedstock neither to produce ethanol nor to cogenerate biomass-based electricity. Complementarily, fuzzy cluster III aggregated the hybrids of higher fiber content, VX12-0180 and VX12-1022. Fiber is essential to feed large-capacity furnace-boiler systems requiring high thermal quality lignocellulosic by-products (Richard \& Anderson, 2014). Summarily, hybrids from fuzzy cluster I were type I, while the hybrids from fuzzy cluster III were type II, due to their lower sucrose to fiber ratio as described in Table 1. 
Table 1. Descriptive analysis of technological quality of cane juice and physicochemical quality of hybrids of energy-cane classified through principal component analysis-linked fuzzy c-means clustering algorithm as renewable resources for production of first-generation ethanol and co-generation of heat and bioelectricity

\begin{tabular}{|c|c|c|c|c|c|c|}
\hline Hybrid & Type & Application & $\begin{array}{l}\text { Soluble solids } \\
\% \text { cane juice }\end{array}$ & $\begin{array}{l}\text { Sucrose } \\
\% \text { cane juice }\end{array}$ & $\begin{array}{l}\text { Purity } \\
\% \text { cane juice }\end{array}$ & $\begin{array}{l}\text { Reducing sugars } \\
\% \text { cane juice }\end{array}$ \\
\hline VX12-0277 & \multirow{4}{*}{ I } & \multirow{4}{*}{ Bioethanol } & 16.20 & 12.50 & 77.30 & 01.00 \\
\hline VX12-1191 & & & 15.60 & 12.00 & 77.00 & 01.00 \\
\hline VX12-1356 & & & 17.10 & 12.90 & 75.30 & 01.10 \\
\hline VX12-1658 & & & 15.60 & 11.40 & 73.10 & 01.15 \\
\hline Mean \pm standa & viation & & $16.10 \pm 00.70$ & $12.20 \pm 00.65$ & $75.70 \pm 01.90$ & $01.10 \pm 00.05$ \\
\hline Coefficient of & lation; \% & & 04.40 & 05.30 & 02.55 & 07.10 \\
\hline VX12-1022 & \multirow{2}{*}{ II } & \multirow{2}{*}{ Bioelectricity } & 15.85 & 11.50 & 72.60 & 01.20 \\
\hline VX12-0180 & & & 13.80 & 09.40 & 67.95 & 01.30 \\
\hline Mean \pm standa & viation & & $14.80 \pm 01.45$ & $10.45 \pm 01.50$ & $70.30 \pm 03.30$ & $01.25 \pm 00.10$ \\
\hline Coefficient of & iation; \% & & 09.80 & 14.20 & 04.70 & 05.70 \\
\hline VX12-0201 & \multirow{2}{*}{ I } & \multirow{2}{*}{ Unqualified } & 12.35 & 07.30 & 59.10 & 01.60 \\
\hline VX12-0046 & & & 14.30 & 09.65 & 67.40 & 01.30 \\
\hline Mean \pm standa & viation & & $13.30 \pm 01.40$ & $08.50 \pm 01.70$ & $63.25 \pm 05.90$ & $01.45 \pm 00.20$ \\
\hline \multirow{2}{*}{\multicolumn{2}{|c|}{ Coefficient of variation; $\%$}} & & 10.35 & 19.60 & 09.30 & 14.60 \\
\hline & & & $\begin{array}{l}\text { Water content } \\
\% \text { cane bagasse }\end{array}$ & $\begin{array}{l}\text { Fiber } \\
\% \text { cane bagasse }\end{array}$ & $\begin{array}{l}\text { Productive yield of sugar } \\
\mathrm{kg} \mathrm{t}^{-1} \text { cane }\end{array}$ & $\begin{array}{l}\text { Productivity of biomass } \\
\mathrm{t} \mathrm{ha}^{-1}\end{array}$ \\
\hline VX12-0277 & \multirow{4}{*}{ I } & \multirow{4}{*}{ Bioethanol } & 08.05 & 24.80 & 86.60 & 84.60 \\
\hline VX12-1191 & & & 08.40 & 22.80 & 86.50 & 87.20 \\
\hline VX12-1356 & & & 08.20 & 24.10 & 90.60 & 90.40 \\
\hline VX12-1658 & & & 10.00 & 24.10 & 81.20 & 95.50 \\
\hline Mean \pm standa & viation & & $08.70 \pm 00.90$ & $23.95 \pm 00.80$ & $86.20 \pm 03.90$ & $89.40 \pm 04.70$ \\
\hline Coefficient of & lation; \% & & 10.40 & 03.50 & 04.50 & 05.25 \\
\hline VX12-1022 & \multirow{2}{*}{ II } & \multirow{2}{*}{ Bioelectricity } & 11.00 & 26.00 & 79.90 & 84.30 \\
\hline VX12-0180 & & & 18.30 & 26.20 & 66.00 & 82.40 \\
\hline Mean \pm standa & viation & & $14.65 \pm 05.20$ & $26.10 \pm 00.15$ & $72.95 \pm 09.80$ & $83.35 \pm 01.35$ \\
\hline Coefficient of & lation; \% & & 35.20 & 00.55 & 13.50 & 01.60 \\
\hline VX12-0201 & \multirow{2}{*}{ I } & \multirow{2}{*}{ Unqualified } & 24.10 & 14.10 & 58.10 & 81.40 \\
\hline VX12-0046 & & & 23.20 & 13.20 & 72.45 & 81.60 \\
\hline Mean \pm standa & viation & & $23.65 \pm 00.65$ & $13.65 \pm 00.65$ & $65.30 \pm 10.15$ & $81.50 \pm 00.15$ \\
\hline Coefficient of & lation; \% & & 02.70 & 02.70 & 15.55 & 00.20 \\
\hline
\end{tabular}

The hybrids W181456, W179460 and W179458 grown by Rao et al. (2007) yielded 8.9, 9.3 and 9.8\% soluble solids. Kim and Day (2011) and Matsuoka et al. (2012) reported soluble solids content in cane juice of energy cane ranged as low as 9.4 to upwards $11.0 \%$. The authors argued total soluble solids content vary drastically depending on genotype, weather conditions and soil fertility, crop management, extend of industrial procedures by sugarcane mill plants, and type of technological analysis. Indeed, the hybrids of energy cane defuzzified as alternative clean energy sources to produce first-generation ethanol were technologically superior than those referenced.

The scientific study by Milanez et al. (2015) on the public policies and competitive impact of second-generation ethanol in the biofuels market reported $8.9 \%$ sucrose in energy cane samples. Kim and Day (2011) and Ceccato-Antonini et al. (2017) assessed 9.6 and $12.1 \%$ sucrose, respectively. The authors emphasized sucrose to fiber ratio is the foremost parameter to categorize energy cane, consistent with this study, in which Euclidian metric measured greater distances between the contents of sucrose and fibers of the hybrids from the fuzzy clusters I and III.

The clones VG11-X1 and VG11-X2 grown by Ceccato-Antonini et al. (2017) yielded $20.3 \%$ and $13.8 \%$ fiber, respectively. Rao et al. (2007) and Kim and Day (2011) found higher contents of $24.5 \%$ and $26.1 \%$ fiber, respectively, in agreement with this study. Fibers refer to secondary metabolites which play pivotal role as 
mechanical barriers to protect crop plants from experiencing adverse effects of herbivore pests, plant lodging and other stressful factors constraining productivity and technological quality of sugar and biomass fields (Kim \& Day, 2011; Matsuoka et al., 2014; Milanez et al., 2015). Therefore, the hybrids from fuzzy cluster III could supply the sugarcane producers with energy cane fields of longer longevity and larger productivity of fiber-rich biomass. High-fiber-yield crops are essential to primary energy supply in both high-income and low-income countries.

According to Matsuoka et al. (2014) and Carvalho-Netto et al. (2014), productivity of dry biomass of energy cane ranged as low as 36.0 to upwards $60.0 \mathrm{t} \mathrm{ha}^{-1}$, inconsistent with the results in this scientific study. Leal et al. (2013) cited energy cane is genetically capable to produce $177.0 \mathrm{t} \mathrm{ha}^{-1}$ dry biomass in stress-free environments. Therefore, crop performance of energy cane is dependent on genotype-environmental relationship. Apart from their higher technological quality of cane juice, the hybrids from fuzzy cluster I had larger productivities of dry biomass than that from fuzzy clusters II and III. Although it does not significant correlated with the principal components, primary and secondary, productivity of dry biomass makes energy cane to be one of the most attractive energy supply pathways to produce high technological quality biofuels and cogenerate electricity in energy industries (Richard \& Anderson, 2014).

From the descriptive analysis, the higher the coefficient of variation, the greater the level of dispersion around the mean. In practice, the higher the standard deviation to mean ratio, the higher the sensitivity of genotype to the environment. On one hand, the hybrids from fuzzy cluster I were lesser sensitive to external agents influencing technological quality of cane juice than the hybrids from fuzzy cluster III. On the other hand, hybrids from fuzzy cluster III were lesser sensitive to external agents influencing physicochemical quality of lignocellulose than the hybrids from fuzzy cluster I. Homogeneity is not only relevant to produce higher quality ethanol, heat and bioelectricity, but also to reduce costs of mechanical harvesting and transportation of feedstock. In general, parameters ranked in increasing order for environmental sensitivity: fiber $<$ productivity of dry biomass $<$ purity $<$ total soluble solids $<$ reducing sugars $<$ productive yield of fermentable $<$ sucrose $<$ water. This is fundamental to further studies on environmental sensitivity parameters in genetic breeding and production of high-technical-quality energy cane.

\subsection{Correlation Analysis}

From the correlogram proposed in Figure 3, total soluble solids positively correlated with sucrose and purity, but negatively with reducing sugars and water. These correlations explained higher technological quality of cane juice from the hybrids classified for production of first-generation ethanol, as well the poorer quality of the hybrids from fuzzy cluster II.

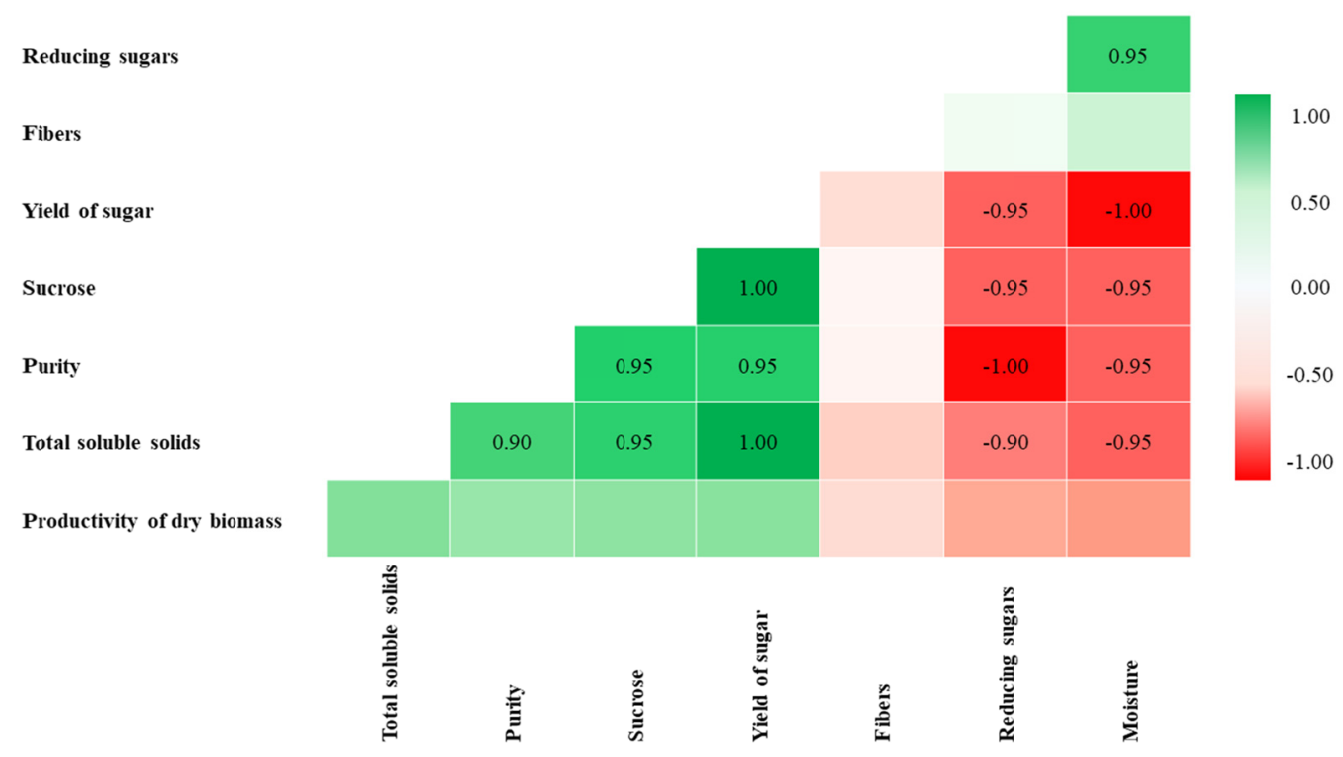

Figure 3. Correlogram of the parameters of technological quality of cane juice and physicochemical quality of hybrids of energy-cane classified through principal component analysis-linked fuzzy c-means clustering algorithm as renewable resources for production of first-generation ethanol and co-generation of heat and bioelectricity 
Other important linear associations were purity positively correlated with sucrose and productive yield of fermentable sugars, but negatively with reducing sugars. Therefore, the higher the sucrose to soluble solids ratio, the richer the cane juice and the larger the productive yield of sugar of hybrids of energy cane. However, the higher the monosaccharides to sucrose ratio, the poorer the technological quality as in the case of the hybrids from fuzzy cluster II. In agreement with this work, other scientific studies reported significant correlations between soluble solids, sucrose, purity, reducing sugars and moisture (Silva et al., 2008; Audilakshimi et al., 2010; Khan et al., 2012).

\section{Conclusion}

The conclusion is, therefore, the hybrids VX12-0277, VX12-1191, VX12-1356 and VX12-1658 prove to be type I energy cane (higher sucrose to fiber ratio) and could serve as renewable energy supply pathways to produce bioethanol, while the hybrids VX12-0180 and VX12-1022 are type II energy cane (lower sucrose to fiber ratio), denoting potential as higher fiber yield biomass sources to feed cogeneration of heat and bioelectricity in high temperature and pressure furnace-boiler system.

\section{References}

Ahmed, A. O., Obeid, A., \& Dafallah, B. (2010). The influence of characters association on behavior of sugarcane genotypes (Saccharum spp.) for cane yield and juice quality. World Journal of Agricultural Sciences, 6(2), 207-211.

Audilakshmi, S., Mall, A. K., Swarnalatha, M., \& Seetharama, N. (2010). Inheritance of sugar concentration in stalk (brix), sucrose content, stalk and juice yield in sorghum. Biomass and Bioenergy, 34(6), 813-820. https://doi.org/10.1016/j.biombioe.2010.01.025

Bahadori, A., Zahedi, G., Zendehboudi, S., \& Jamili, A. (2014). Estimation of the effect of biomass moisture content on the direct combustion of sugarcane bagasse in boilers. International Journal of Sustainable Energy, 33(2), 349-356. https://doi.org/10.1080/14786451.2012.748766

Carvalho-Netto, O. V., Bressiani, J. A., Soriano, H. L., Fiori, C. S., Santos, J. M., Barbosa, G. V., \& Pereira, G. A. (2014). The potential of the energy cane as the main biomass crop for the cellulosic industry. Chemical and Biological Technologies in Agriculture, 1(1), 1-20. https://doi.org/10.1186/s40538-014-0020-2

Ceccato-Antonini, S. R., Bassi, A. P. G., Paraluppi, A. L., Santos, E. G. D. D., \& Matsuoka, S. (2017). Deterioration and fermentability of energy cane juice. Ciência Rural, 47(9), 1-7. https://doi.org/10.1590/ 0103-8478cr20160860

Defante, L. R., Vilpoux, O. F., \& Sauer, L. (2018). Rapid expansion of sugarcane crop for biofuels and influence on food production in the first producing region of Brazil. Food Policy, 79, 121-131. https://doi.org/ 10.1016/j.foodpol.2018.06.005

Goldemberg, J., Mello, F. F., Cerri, C. E., Davies, C. A., \& Cerri, C. C. (2014). Meeting the global demand for biofuels in 2021 through sustainable land use change policy. Energy Policy, 69, 14-18. https://doi.org/10.1016/j.enpol.2014.02.008

Gouy, M., Luquet, D., Rouan, L., Martiné, J. F., Thong-Chane, A., Costet, L., \& Gozé, E. (2015). Site and Saccharum spontaneum introgression level drive sugarcane yield component traits and their impact on sucrose yield in contrasted radiation and thermal conditions in La Réunion. Field Crops Research, 171, 99-108. https://doi.org/10.1016/j.fcr.2014.11.002

Jolliffe, I. T., \& Cadima, J. (2016). Principal component analysis: A review and recent developments. Philosophical Transaction of the Royal Society, Series A, 374(2065), 1-16. https://doi.org/10.1098/ rsta.2015.0202

Khan, I. A., Bibi, S., Yasmin, S., Khatri, A., Seema, N., \& Abro, S. A. (2012). Correlation studies of agronomic traits for higher sugar yield in sugarcane. Pakistan Journal of Botany, 44(3), 969-971.

Kim, M., \& Day, D. (2011). Composition of sugar cane, energy cane, and sweet sorghum suitable for ethanol production at Louisiana sugar mills. Journal of Industrial Microbiology \& Biotechnology, 38(7), 803-807. https://doi.org/10.1007/s10295-010-0812-8

Leal, M. R. L. V., Walter, A. S., \& Seabra, J. E. A. (2013). Sugarcane as an energy source. Biomass Conversion and Biorefinery, 3(1), 17-26. https://doi.org/10.1007/s10295-010-0812-8

Mansoori, M., Jordi, A., Mashal, M., \& Mashal, M. (2016). Effects of salinity stress on nutrient uptake of sugarcane genotypes. Nova Journal of Engineering and Applied Sciences, 3(3), 1-8. 
Matsuoka, S., Bressiani, J., Maccheroni, W., \& Fouto, I. (2012). Bioenergia da cana. Cana-de-açúcar: Bioenergia, Açúcar e Álcool, 1, 548-576.

Matsuoka, S., Kennedy, A. J., Santos, E. G. D. D., Tomazela, A. L., \& Rubio, L. C. S. (2014). Energy cane: Its concept, development, characteristics, and prospects. Advances in Botany, 2014, 1-13. https://doi.org/ $10.1155 / 2014 / 597275$

Milanez, A. Y., Nyko, D., Valente, M. S., Sousa, L. C., Bonomi, A. M. F. L. J., Jesus, C. D. F. D., \& Junqueira, T. L. (2015). De promessa à realidade: Como o etanol celulósico pode revolucionar indústria da cana-de-açúcar: Uma avaliação do potencial competitivo e sugestões de política pública. BNDES Setorial, 41, 237-294.

Nayak, J., Naik, B., \& Behera, H. S. (2015). Fuzzy c-means (FCM) clustering algorithm: a decade review from 2000 to 2014. In L. Jain, H. Behera, J. Mandal, \& D. Mohapatra (Ed.), Computational Intelligence in Data Mining (Vol. 2, pp. 133-159). New Delhi: Springer. https://doi.org/10.1007/978-81-322-2208-8_14

R Core Team, (2018). R: A language and environment for statistical computing. R Foundation for Statistical Computing, Vienna, Austria.

Rao, P. S., Davis, H., \& Simpson, C. A. R. L. (2007). New sugarcane varieties and year round sugar and ethanol production with bagasse-based cogeneration in Barbados and Guyana. International Society of Sugarcane Technology, 26,169-1176.

Rea, R., Sousa-Vieira, O., Díaz, A., Ramón, M., Briceño, R., George, J., \& Balzano-Nogueira, L. (2016). Genotype-environment interaction, megaenvironments and two-table coupling methods for sugarcane yield studies in Venezuela. Sugar Tech, 18(4), 354-364. https://doi.org/10.1007/s12355-015-0407-9

Richard, E. P., \& Anderson, W. F. (2014). Sugarcane, energy cane and napier-grass. Cellulosic Energy Cropping Systems, 1, 91-108. https://doi.org/10.1002/9781118676332.ch6

Santchurn, D., Ramdoyal, K., Badaloo, M. G. H., \& Labuschagne, M. (2012). From sugar industry to cane industry: investigations on multivariate data analysis techniques in the identification of different high biomass sugarcane varieties. Euphytica, 185(3), 543-558. https://doi.org/10.1007/s10681-012-0682-4

Silva, M. D. A., Silva, J. A. G. D., Enciso, J., Sharma, V., \& Jifon, J. (2008). Yield components as indicators of drought tolerance of sugarcane. Scientia Agricola, 65(6), 620-627. https://doi.org/10.1590/S0103-90162008 000600008

Viana, R. S., May, A., Mateus, G. P., Neto, A. D. R., \& Lopes, P. R. M. (2017). Aspectos tecnológicos de sorgo-sacarino submetido à aplicação de maturadores químicos. Científica, 45(3), 204-213. https://doi.org/ $10.15361 / 1984-5529.2017 \mathrm{v} 45 \mathrm{n} 3 \mathrm{p} 204-213$

\section{Copyrights}

Copyright for this article is retained by the author(s), with first publication rights granted to the journal.

This is an open-access article distributed under the terms and conditions of the Creative Commons Attribution license (http://creativecommons.org/licenses/by/4.0/). 